\title{
SOIL CARBON DIOXIDE EFFLUX RESPONDS TO LAND-USE CHANGES IN THE SUB-URBAN REGIONS OF NANJING, CHINA
}

\author{
LV, L. G. - WU, Z. P. -WANG, J. X. - WU, S. H. ${ }^{*}$-ZHOU, S. L.* \\ School of Geographic and Oceanographic Sciences, Nanjing University \\ 163 Xianlin Road, Nanjing 210023, China \\ (phone: +86-158-959-93201; fax: +86-25-835-92686) \\ *Corresponding author \\ e-mail:wsh@nju.edu.cn; zhousl@nju.edu.cn \\ (Received $13^{\text {th }}$ Aug 2015; accepted $31^{\text {st }}$ Mar 2016)
}

\begin{abstract}
The aim of this study was to assess the influence of urbanization on soil carbon dioxide efflux. We investigated how the soil environment affects the soil carbon dioxide efflux in native grassland, residential lawns and agricultural land. Continuous measurements of the soil carbon dioxide efflux were made once a week for a 10-week period during July-September 2013 in Nanjing China. Our results demonstrated that the soil carbon dioxide efflux significantly decreased during the10-week period in the three land-use types. Soil carbon dioxide efflux in urban lawns was the highest among the three land-use types in the following order: residential land > agricultural land > native grassland. The soil water-soluble organic carbon (WSOC), the labile organic carbon (LOC), and the basal respiration, as covariates, did not significantly influence the soil carbon dioxide efflux. The soil temperature and land-use type had significant contributions to the carbon efflux. A higher soil temperature in the lawns was attributed to the urban heat island effect. Our data suggest that human-induced land-use changes, such as urbanization and agricultural practice, could enhance the local soil carbon dioxide emissions, especially when urban development increased the local soil temperature.
\end{abstract}

Keywords: backward elimination stepwise linear regression, soil carbon dioxide efflux, soil moisture, soil temperature, urbanization

\section{Introduction}

Soil carbon dioxide efflux is a major contributor to the carbon emission from the terrestrial ecological system into the atmosphere and is an important source of atmospheric carbon dioxide (Hou, 2011) that is associated closely with the global terrestrial-atmospheric carbon exchanges. Approximately $25 \%$ of global carbon emissions is derived from land-use change and is the second largest source of humaninduced greenhouse gas emissions (Houghton, 2003; Zheng et al., 2011). To date, urbanization is increasing in developing countries, especially in China, and is now one of the burgeoning types of land-use change that is altering ecosystem processes (Pickett et al., 2011; Siciliano, 2012). The urbanization process can change the natural and agricultural landscapes into urban commercial, industrial, greenbelt, and residential uses, thereby altering the carbon stocks and carbon fluxes through the destruction of habitat, climate change, and urban pollutant deposition (Pouyat et al., 2002; Fenn et al., 2003; Trusilova and Churkina, 2008; Duan et al., 2013). Thus, a question of increasing interest is how urban land-use impacts ecosystem processes, such as soil carbon cycling.

In fact, the influences of urbanization on soil carbon dioxide efflux depend on climatic conditions, the urban land-use and vegetation types. Koerner and Klopatek (2010) found that the soil respiration rates along an urban-rural gradient in a desert landscape in Phoenix, Arizona. The research on carbon dynamics in urban and rural forests in humid Baltimore demonstrated that soil respiration rates were higher at the 
urban sites (Groffman et al., 2006). Kaye et al. (2005) reported that urban ecosystems had dramatically altered the soil respiration compared with native grasslands and agricultural ecosystems. Similarly, Bowne and Johnson (2013) observed that the carbon dioxide efflux of the residential lawns was significantly higher than that of the corn fields in Elizabethtown, PA. Obviously, the spatial-temporal variability of the soil carbon is controlled by the soil temperature, soil moisture, photosynthetic nutrition supply to roots, and substrate availability (Balogh et al., 2011). Sheng et al. (2010) found that soil respiration rates were significantly reduced following the conversion of natural forest to agricultural land in subtropical China, which was explained by the decrease of the topsoil organic carbon and the light-fraction organic carbon storages. For two decades, however, most of studies on the effects of urbanization on carbon dynamics have mainly focused on temperate urban ecosystems (Carlisle et al., 2006; Kellman et al., 2007; Raciti et al., 2011); little is known regarding the soil carbon dioxide efflux response to land-use changes in tropical-subtropical urban ecosystems.

Therefore, we investigated: the potential influence of urbanization on carbon dynamics by monitoring the soil carbon dioxide efflux in subtropical urban ecosystems, such as the residential lawns, native grasslands and agricultural fields in Nanjing, China. More specifically, the objective of this study was to investigate: a) the soil carbon dioxide efflux differences among three land-use types in the suburban environment and b) the main factors influencing the soil carbon dioxide efflux. Based on previous research on the variations of the soil carbon dioxide efflux in urban ecosystems, we hypothesized that the soil carbon dioxide efflux in residential lawns would be higher than that in the adjacent agricultural land and native grassland due to the urban heat effect.

\section{Materials and methods}

\section{Study area and field experiment}

The field experiment was conducted from July to September 2013 in the Xianlin Campus of the Nanjing Sport Institute $\left(32^{\circ} 6^{\prime} 45.3^{\prime \prime}\right.$ - 32 $2^{\circ} 35.6^{\prime \prime} \mathrm{N}, 118^{\circ} 57^{\prime} 51.5^{\prime \prime}$ $118^{\circ} 58^{\prime} 34.8^{\prime \prime} \mathrm{E}$ ), which is located in the northeast of Nanjing, China (Fig. 1). Nanjing, with a total land area of 6,598 square kilometers, is situated in one of the largest economic zones of China, the Yangtze River Delta, which is part of the downstream Yangtze River drainage basin. With a total population of 8.16 million and an urban population of 6.55 million, Nanjing is the second-largest commercial center in the East China region, after Shanghai. A maritime subtropical monsoon climate covers this region, which has a mean annual air temperature of $18.7^{\circ} \mathrm{C}$ and a mean annual rainfall of $1106 \mathrm{~mm}$. A typical urban and agricultural land-use change sequence in this region was chosen, including residential lawns, agricultural land, and native grassland, which allows us to compare the undisturbed soil and the disturbed soil. Three fields of each land-use type were studied, and the distance between these fields ranged from 250 to 1400 meters. The native grassland has had an absence of human mediated disturbance for at least 30 years. The native grassland was covered mainly by native herbaceous species, such as Humulus scandens (Lour.) Merr (45\%), Conyza canadensis L. (25\%), Juncus effuses L. (18\%) and Solidago altissima (12\%). Agricultural land was in rotation with wheat (Triticum aestivum L.) and rape (Brassica campestris L.). Approximately $225-300 \mathrm{~kg} \mathrm{ha}^{-1}$ of nitrogenous fertilizer was applied to the rape field during the cultivation, and the wheat field was fertilized using approximately 180-215 
$\mathrm{kg} \mathrm{ha}^{-1}$ of nitrogenous fertilizer. Our experiment began approximately two weeks after the harvest of the wheat. During the study, the agricultural fields were no-till. The agricultural fields have been in cultivation for over 30 years since conversion from native grassland. To study the impact of urban land-use, three 10-year old residential lawn fields were selected for the study, which were transformed from agricultural fields. These lawns were treated with nitrogenous fertilizer at a rate of approximately 150-225 $\mathrm{kg} \mathrm{ha}^{-1}$ each March. Moreover, manila grass (Zoysia japonica) and tall fescue grass ( Festuca arundinacea) were planted in the lawns that were mowed once a month, after which the residue was removed from the lawns. These land-uses are similar in topography and soil type, with elevations varying from 19.16 to $24.88 \mathrm{~m}$. The loam soil at the experimental site is a Haptic Luvisol derived from the Xiashu loess. None of the study sites were irrigated because the study occurred during the rainy season in Nanjing.

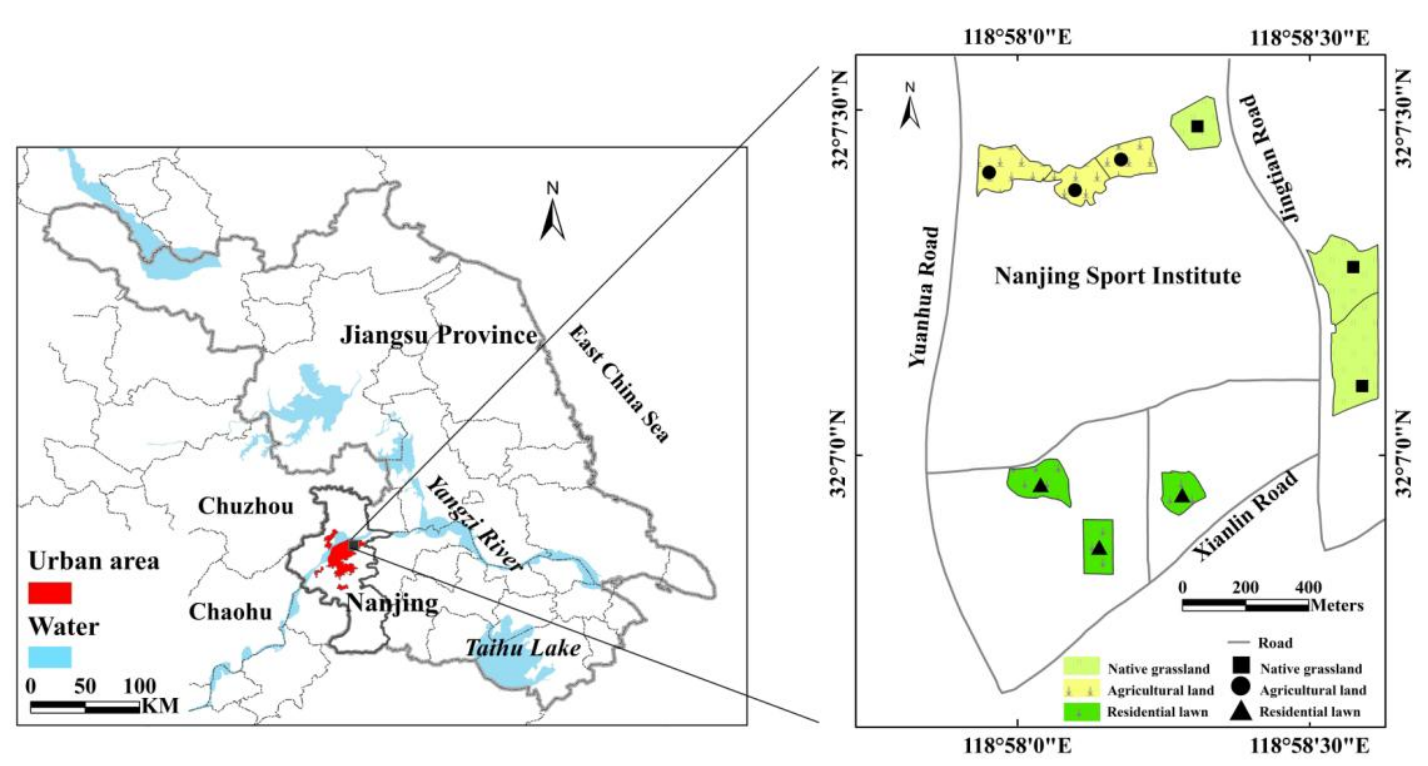

Figure 1. Geographic location and land-use situation of the study site

\section{Soil carbon dioxide efflux, temperature, and moisture measurements}

Three polyvinyl chloride (PVC) collars (11-cm inner diameter and 20-cm height) were randomly inserted into the soil at each location for continuous soil carbon dioxide efflux measurement throughout the entire study period. The collars were inserted in the soil of a $10-\mathrm{cm}$ depth to monitor the soil carbon dioxide efflux. Sampling areas in the agricultural fields were of soil between the wheat rows. The vegetation inside the collar was clipped to the soil surface to avoid the interference of aboveground plant respiration during measurements. Meanwhile, we attempted to not disturb the soil to minimize root disturbance and soil porosity. We measured the soil carbon dioxide efflux at three locations per field, for a total of 27 measurements once a week on a sampling day from 11 July to 12 September 2013. The measuring time per field was over a 7 min period. Measurements in three land-use types were performed in random visits to each site between 8:00 and 11:30 (Beijing Time) in the absence of rain. For determining the daily variation of soil respiration, three fields per land-use type were measured continuously every 15 min between 8:00-20:00 (Beijing Time) on 22 September 2013. The soil 
carbon dioxide efflux and temperature were measured using a Leaf Chamber \& Soil Respiration Analysis System (LCpro ${ }^{+}$, ADC Bioscientific Ltd.) with a $10-\mathrm{cm}$ temperature probe. Soil moisture was measured using a Time Domain Reflectometry unit (Model TRIME-PICO, Germany) at a 0-10 $\mathrm{cm}$ depth at each location (Zhu et al., 2012).

\section{Soil property determinations}

Three randomized topsoil samples $(0-10 \mathrm{~cm})$ in each land-use field were collected using a sampling ring knife for soil property determinations on August 27, 2013. The soil bulk density $(0-10 \mathrm{~cm})$ was measured using the cutting ring method $\left(100 \mathrm{~cm}^{3}\right)$ according to Sheng et al. (2010). Approximately 500-g subsamples were air-dried at room temperature, homogenized, and then ground in an agate mortar and sieved to 2 $\mathrm{mm}, 0.25 \mathrm{~mm}$ and $0.149 \mathrm{~mm}$ for further analysis. Total carbon and nitrogen in each of the 27 samples were determined by the elemental combustion of $25.0 \mathrm{mg}$ of dried 0.149-mm sieved soil using a CHN elemental analyzer (Heraeus Elementar Vario EL, Germany) in Modern Analysis Center of Nanjing University. Labile organic carbon (LOC) was determined using the modified method described by Blair et al,. (1995). Approximately $15 \mathrm{~g}$ of the $0.25-\mathrm{mm}$ sieved soil was added into $30-\mathrm{mL}$ plastic centrifuge tubes with $25 \mathrm{~mL}$ of $333 \mathrm{mmol} \mathrm{L}^{-1} \mathrm{KMnO}_{4}$. The centrifuge tubes were tumbled for $1 \mathrm{~h}$ at $25{ }^{\circ} \mathrm{C}$, centrifuged for $5 \mathrm{~min}$ at $2000 \mathrm{rpm}$. The supernatants were diluted with deionized water (v/v, 1:250). The absorbance of the diluted samples was read on a split beam spectrophotometer at $565 \mathrm{~nm}$. Water-soluble organic carbon (WSOC) and basal respiration were analyzed according to Wei et al. (2014), with a minor modification. The soil sample (15 g of $2 \mathrm{~mm}$ sieved) was mixed with $30 \mathrm{~mL}$ of distilled water, shaken for $2 \mathrm{~h}$ at $25^{\circ} \mathrm{C}$, and then centrifuged at $5000 \mathrm{rpm}$ at $4^{\circ} \mathrm{C}$ for $15 \mathrm{~min}$. The supernatant was filtered through a $0.45-\mu \mathrm{m}$ carbon-free membrane for water-soluble organic carbon (WSOC). Regarding basal respiration, approximately $50 \mathrm{~g}$ of soil (2 $\mathrm{mm}$ sieved) were added into plastic bottles $(500 \mathrm{~mL})$. The soil water content was adjusted to $60 \%$ of full water holding capacity and then pre-incubated in the dark for 7 days at $25{ }^{\circ} \mathrm{C}$ to restore the microbial activity for soils. Next, in each jar, a beaker with $10 \mathrm{~mL}$ of $0.6 \mathrm{~mol} \mathrm{~L}{ }^{-1}$ $\mathrm{NaOH}$ was placed to absorb the evolved carbon dioxide during the incubation, and the solution of $\mathrm{NaOH}$ was renewed after 1, 2, 3, 4, 5 and $6 \mathrm{~d}$. The carbon dioxide trapped in the $\mathrm{NaOH}$ was determined by back-titration of excess $\mathrm{NaOH}$ with $1.5 \mathrm{~mol} \mathrm{~L}^{-1}$ after precipitation with $1 \mathrm{~mol} \mathrm{~L}^{-1} \mathrm{BaCl}_{2}$. Blank samples containing no soil and samples of a standard soil were analyzed in each run. The calculation of the basal respiration was determined using the day average of the 7-day period cumulative $\mathrm{CO}_{2}$ efflux $\left(\mathrm{mg} \mathrm{CO} \mathrm{CO}_{2}-\mathrm{C}\right.$ $\mathrm{kg}^{-1} \mathrm{~d}^{-1}$ ). To determine the influence of the surrounding land-use on soil temperature, we extracted the information urban land-use within $175 \mathrm{~m}$ of each experimental site from the Second National Land Survey Dataset of China to calculate the area of developed land-use in a geographic information system (ArcGIS 10.0, ESRI) according to Gunawardhana and Kazama (2012).

\section{Data analysis}

The temporal-variability data of the soil carbon dioxide efflux were analyzed using a repeated measures general linear model (GLM). The weekly differences of the mean soil carbon dioxide efflux, soil temperature and soil moisture for three land-use types soil were analyzed using the respective GLM. The soil carbon content, nitrogen content, 
water-soluble organic carbon (WSOC), labile organic carbon (LOC), and basal respiration acted as covariates and were added into the GLM. The influence of the soil temperature, soil moisture and land-use types on the soil carbon dioxide efflux, independent of time, was analyzed using backward elimination stepwise linear regressions. The soil carbon dioxide efflux was $\log _{10}$ transformed because the soil carbon dioxide efflux did not correlate linearly with the soil temperature. The differences of the soil carbon content, nitrogen content, water-soluble organic carbon (WSOC), labile organic carbon (LOC), and basal respiration across three land-use types were compared by factorial ANOVA with $\alpha=0.05$ (Duncan's multiple range test). All of the statistical analyses were performed in SPSS 19.0 (IBM SPSS, New York) and SigmaPlot 12.0 (Systat Software Inc., San Jose, CA).

\section{Results}

\section{Soil Properties}

As presented in Table 1, the soil carbon and nitrogen contents did not significantly differ $\left(\mathrm{F}_{2,24}=2.432, \mathrm{p}=0.109 ; \mathrm{F}_{2,24}=1.449, \mathrm{p}=0.255\right)$ in the samples from the lawns, agricultural lands and native grasslands. The soil labile organic carbon (LOC), watersoluble organic carbon (WSOC) and basal respiration $\left(\mathrm{F}_{2,24}=3.911, \mathrm{p}=0.034 ; \mathrm{F}_{2,24}=\right.$ $6.670, \mathrm{p}=0.005 ; \mathrm{F}_{2,24}=6.954, \mathrm{p}=0.004$, respectively) in agricultural lands and urban lawns were significantly lower than those in native grasslands. The soil carbon contents and nitrogen contents as covariates were incorporated into the GLM. The results suggested that the soil carbon contents $\left(\mathrm{F}_{1,}{ }_{4}=0.522, \mathrm{p}=0.510\right)$ and nitrogen contents $\left(\mathrm{F}_{1}, 4=6.270, \mathrm{p}=0.066\right)$ had no significant influence on the soil carbon dioxide efflux, but they decreased the significance of land-use on efflux over time $\left(\mathrm{F}_{2,4}=41.986, \mathrm{p}=\right.$ 0.002). LOC, WSOC and basal respiration as covariates were also added into the GLM. The results exhibited that LOC $\left(\mathrm{F}_{1,3}=6.439, \mathrm{p}=0.085\right)$, WSOC $\left(\mathrm{F}_{1,3}=0.321, \mathrm{p}=\right.$ $0.610)$ and basal respiration $\left(\mathrm{F}_{1,3}=8.364, \mathrm{p}=0.063\right)$ did not significantly influence the soil carbon dioxide efflux, but it also reduced the effect of land-use on the efflux over time $\left(\mathrm{F}_{2,3}=5.841, \mathrm{p}=0.092\right)$.

Table 1. Selected soil ( $0-20 \mathrm{~cm})$ and surrounding development characteristics of three landuse types (native grassland, agricultural land and residential lawns) in the study site of Nanjing, China. Values are means \pm standard errors $(n=9)$, and the significant differences $(p<0.05)$ between the land-use types are noted using superscripts $a, b, c . C=$ carbon; $N=$ nitrogen; $L O C=$ labile organic carbon; $W S O C=$ water-soluble organic carbon.

\begin{tabular}{l|l|l|l}
\hline \multirow{2}{*}{ Experimental site description } & \multicolumn{2}{l}{ Land-use } \\
\cline { 2 - 4 } & Native grassland & Agricultural land & Residential lawns \\
\hline Bulk density $\left(\mathrm{g} \mathrm{cm}^{-3}\right)$ & $1.34 \pm 0.07 \mathrm{a}$ & $1.18 \pm 0.00 \mathrm{~b}$ & $1.40 \pm 0.01 \mathrm{a}$ \\
\hline Carbon content $\left(\mathrm{g} \mathrm{kg}^{-1}\right)$ & $11.50 \pm 0.40 \mathrm{a}$ & $12.73 \pm 0.53 \mathrm{a}$ & $11.40 \pm 0.19 \mathrm{a}$ \\
\hline Nitrogen content $\left(\mathrm{g} \mathrm{kg}^{-1}\right)$ & $1.13 \pm 0.02 \mathrm{a}$ & $1.30 \pm 0.03 \mathrm{a}$ & $1.13 \pm 0.05 \mathrm{a}$ \\
\hline $\mathrm{LOC}\left(\mathrm{g} \mathrm{kg}^{-1}\right)$ & $2.56 \pm 0.11 \mathrm{a}$ & $2.10 \pm 0.06 \mathrm{~b}$ & $2.16 \pm 0.17 \mathrm{~b}$ \\
\hline WSOC $\left(\mathrm{mg} \mathrm{kg}^{-1}\right)$ & $144.91 \pm 4.57 \mathrm{a}$ & $131.35 \pm 2.70 \mathrm{~b}$ & $124.64 \pm 4.44 \mathrm{~b}$ \\
\hline Basal respiration $\left(\mathrm{mg} \mathrm{CO}_{2}-\mathrm{C} \mathrm{kg} \mathrm{d}^{-1}\right)$ & $15.50 \pm 0.48 \mathrm{a}$ & $12.95 \pm 0.55 \mathrm{~b}$ & $13.71 \pm 0.43 \mathrm{~b}$ \\
\hline Impervious surface area $(\%)$ & $4.46 \pm 0.72 \mathrm{c}$ & $16.47 \pm 1.15 \mathrm{~b}$ & $30.49 \pm 1.27 \mathrm{a}$ \\
\hline
\end{tabular}




\section{Soil carbon dioxide efflux}

The soil carbon dioxide efflux of three land-use types significantly decreased over 10 weeks $\left(\mathrm{F}_{9,54}=5.453, \mathrm{p}<0.001 ;\right.$ Fig. $\left.2 a\right)$. The mean soil carbon dioxide efflux was significantly different among the three land-use types $\left(\mathrm{F}_{2,6}=25.745, \mathrm{p}=0.001 ;\right.$ Fig. $\left.2 a\right)$ in the following order: residential lawn $\left(4.37 \pm 0.317 \mu \mathrm{mol} \mathrm{co}_{2} \mathrm{~m}^{-2} \mathrm{~s}^{-1}\right)>$ agricultural land $\left(2.9 \pm 0.354 \mu \mathrm{mol} \mathrm{co}_{2} \mathrm{~m}^{-2} \mathrm{~s}^{-1}\right)>$ native grassland $\left(1.21 \pm 0.164 \mu \mathrm{mol} \mathrm{co} 2 \mathrm{~m}^{-2} \mathrm{~s}^{-1}\right)$. The mean soil carbon dioxide efflux of residential lawns was 1.51 and 3.61 times higher than those of agriculture land and native grassland, respectively.

The diurnal carbon dioxide efflux of soil for three land-use types exhibited a unimodal pattern peaking at 13:00 (Fig. 2b). Compared to the native grasslands, the diurnal variation of soil respiration in lawns and agricultural were greater over the 12hour measurement. In addition, the mean diurnal soil carbon dioxide efflux of lawns and agricultural fields was higher than that of native grasslands $\left(F_{2,6}=33.395, p=0.001\right)$, as was also observed in the weekly measurements of the soil carbon dioxide efflux.
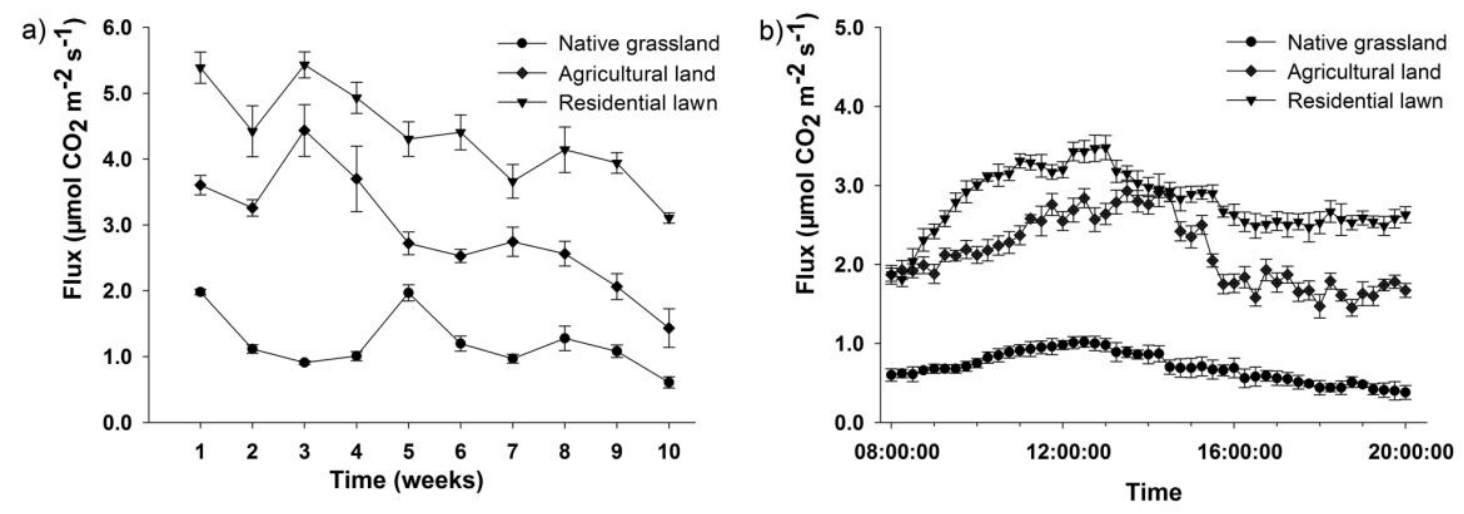

Figure 2. Soil carbon dioxide efflux from native grassland, agricultural land, and residential lawn in Nanjing, China. Points are the means \pm s.e. a) Means from each site type from 11 July to 12 September, 2013. b) Diurnal variation from 8:00 to 20:00 on 22 September 2013.

\section{Soil temperature and moisture for the three land-use types}

The mean soil temperature of all land-use types decreased significantly over time $\left(\mathrm{F}_{9}\right.$, ${ }_{54}=284.187, \mathrm{p}<0.001 ;$ Fig. $3 a$ ), whereas the mean soil moisture generally increased during the duration of the experiment $\left(\mathrm{F}_{9,54}=35.773\right.$, $\mathrm{p}<0.001 ;$ Fig. $\left.3 b\right)$. Both the soil temperature and moisture for each of the three land-use types differed significantly from each other over the 10 weeks $\left(\mathrm{F}_{2,6}=218.374, \mathrm{p}<0.001 ; \mathrm{F}_{2,6}=27.229, \mathrm{p}<0.001\right.$; Fig. $3 a, b)$. Residential lawns had significantly higher soil temperatures compared to wheat and native grasslands over the duration of the study, while the soil moisture ranged between $20 \%$ and $45 \%$ among all land-use types, following the order: native grassland $>$ residential lawn > agricultural land. 

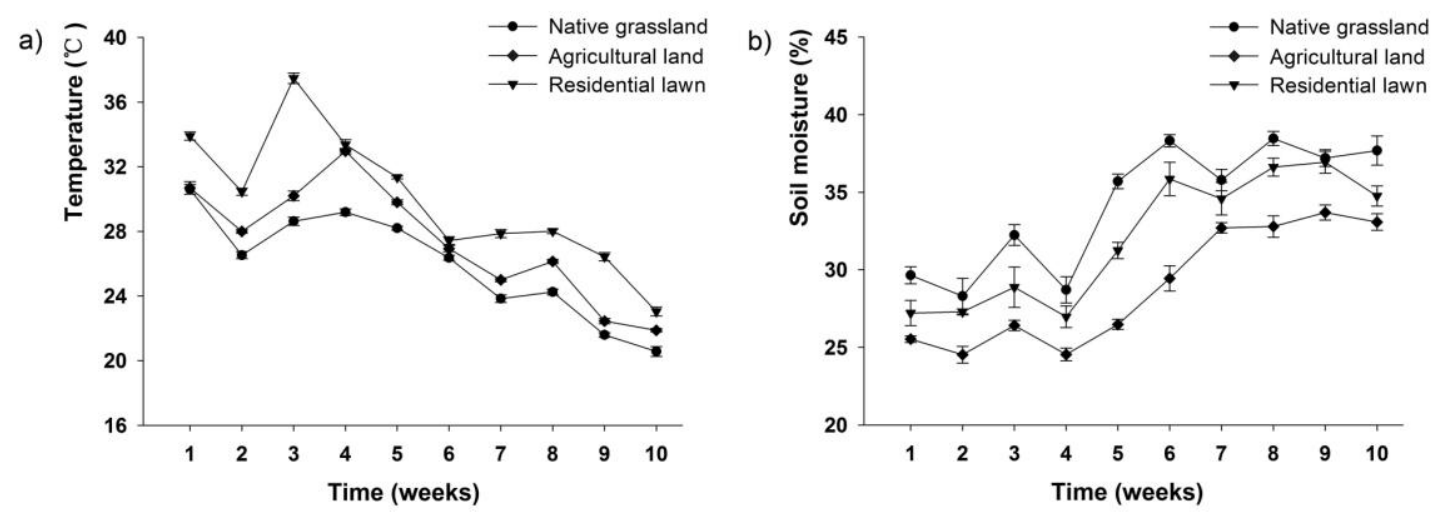

Figure 3. Mean \pm s.e. of (a) soil temperature and (b) soil moisture from the sites of native grassland, agricultural land, and residential lawns from July 11 to September 12, 2013 in Nanjing, China.

\section{Soil carbon dioxide efflux responses to land-use change}

To investigate the multiple factors influencing soil respiration, a backward elimination stepwise linear regression model was used to analyze the influence of soil temperature, soil moisture and the land-use types on soil carbon dioxide efflux. Our results indicated that both land-use type and soil temperature had a significant influence on soil carbon dioxide $\left(\mathrm{R}^{2}=0.783, \mathrm{~F}_{2}, 87=161.410, \mathrm{p}<0.001\right)$. Based on the model, the soil carbon dioxide efflux was significantly influenced by the land-use type $\left(\mathrm{R}^{2}=0.686\right.$, $\mathrm{F}_{1},{ }_{88}=192.101, \mathrm{p}<0.001 ;$ Fig. $\left.4 a\right)$. The soil temperature significantly affected the soil carbon dioxide efflux $\left(\mathrm{R}^{2}=0.396, \mathrm{~F}_{1}, 88=57.802\right.$, $\mathrm{p}<0.001 ;$ Fig. $\left.4 b\right)$. The soil moisture also significantly influenced the soil carbon dioxide efflux $\left(\mathrm{R}^{2}=0.143, \mathrm{~F}_{1,88}=14.815\right.$, $\mathrm{p}$ $<0.001$; Fig. $4 c$ ), but it reduced the significance of the multiple-factor regression model $(\mathrm{t}=-0.884, \mathrm{p}=0.042)$ after it was added into the model.
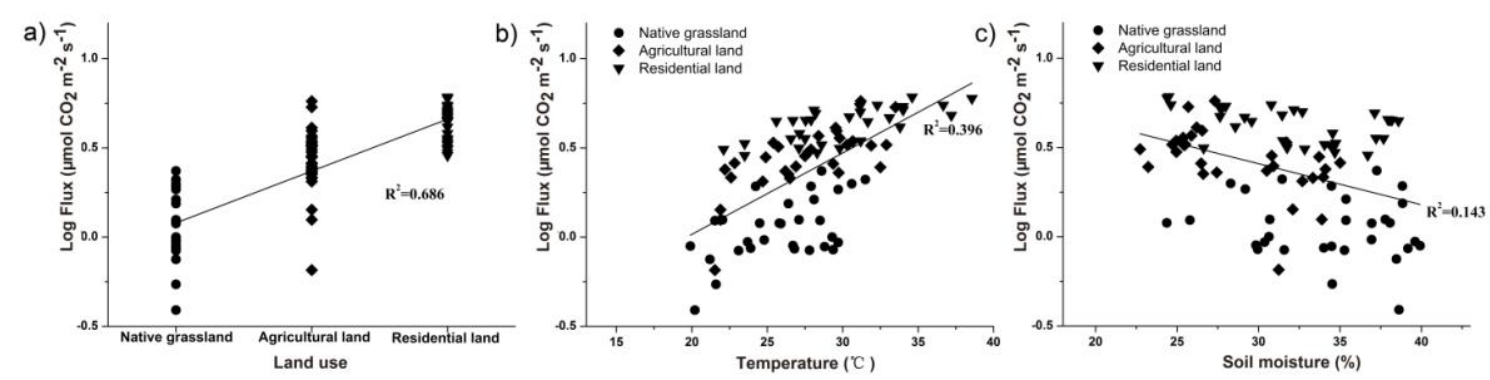

Figure 4. Influence on soil carbon dioxide efflux of (a) land-use $\left(R^{2}=0.686, F_{1,88}=192.101, p\right.$ $<0.001)$, (b) soil temperature $\left(R^{2}=0.396, F_{1,88}=57.802, p<0.001\right)$, and (c) soil moisture $\left(R^{2}\right.$ $\left.=0.144, F_{1}, 88=14.815, p=0.010\right)$. There is no significant influence from soil moisture to soil carbon dioxide; after soil moisture was added to the model, it reduced the significance of the model.

\section{Discussions}

Anthropogenic land-use changes, such as urbanization, agricultural cultivation, and afforestation, often not only alter carbon stocks but also possibly alter carbon efflux 
(Schimel et al., 1997). Most of the literature suggests that human-induced land-use change could reduce the carbon content in the soil (Davidson and Ackerman, 1993; Houghton, 1994; Murty et al., 2002; Zhao et al., 2012). However, in the present study, the results suggested that the soil carbon and nitrogen content were not significantly affected by urban or agricultural land-use and did not significantly influence the soil carbon dioxide efflux, according to the GLM (Table 1). The similarity in carbon and nitrogen concentrations among the three land-use types is likely because current management practices in lawns and wheat field includes fertilizer applications, and carbon is returned to agricultural soils through wheat straw residues (Tian et al., 2010). In the study by Bowne and Johnson (2013), the carbon concentrations between the lawns and corn fields did not significantly differ due to the increasing carbon input into the soil under no-till management (Powlson et al., 2011). The reason why the carbon and nitrogen content as covariates had no significant effect on soil carbon dioxide efflux after analysis with repeated measures was because the two covariates reduced the power from 0.999 to 0.987 , resulting in an increase in the probability of committing a type III error. LOC, WSOC and basal respiration were significantly lower for residential lawns and native grassland, and these covariates also did not significantly influence the soil carbon dioxide efflux, according to the GLM (Table 1). The phenomena may be explained by the fact that higher soil microbe activity and available carbon fractions in non-till field increase the soil microbe respiration, but not enough to affect the total carbon dioxide efflux (Chu et al., 2006).

Meanwhile, we found that the mean weekly soil respiration rates of anthropogenic land-use changes (residential lawns and agricultural fields) in the subtropical city were significantly higher than those of native grasslands, which supports our hypothesis that soil carbon dioxide efflux in urban lawns would be highest (Fig. 1). The soils from urban lawns also had an increased soil carbon content relative to soil from corn fields in the temperate northeast United States, according to Bowne and Johnson (2013). Groffman et al., (2009) found an equal or higher efflux from managed lawns compared to forest soils in Baltimore, MD. Similarly, in arid and semiarid ecosystems, Koerner and Klopatek (2002) reported a greater carbon dioxide efflux in human-controlled ecosystems, such as lawns, golf courses, and agriculture, than in native ones in the Phoenix, AZ, metropolitan area.

Generally, the spatial-temporal variations of the soil carbon dioxide efflux results from a combined effect of root growth and soil environment characteristics, such as microorganisms, temperature, and moisture (Norman et al., 1997; Davidson et al., 1998). The soil temperature and soil moisture are the most important factors in the soil environment controlling the soil carbon effluxes (Raich and Potter, 1995; Koerner and Klopatek, 2002; Ni et al., 2012). In our study, residential lawn sites had the highest average temperature (Fig. 4a), which can explain why the soil carbon dioxide efflux was greater in residential lawns than in agricultural land and native grassland during the study period. In addition, the change of diurnal carbon dioxide efflux was also significantly affected by the diurnal variation of the soil temperature (Fig. 2b). A similar study demonstrated that the soil temperature had a strongly exponential positive correlation with the soil respiration rates for all land-use sites (Sheng et al., 2010). A higher soil temperature can stimulate the turf grass roots and enhance biological decomposition by microbes, thereby releasing carbon dioxide (McCulley et al., 2007; Kaur et al., 2010). An urban heat island effect contributes to the higher soil temperatures in residential lawns as a consequence of more intensive urban 
development (Gunawardhana and Kazama, 2012; Bowne and Johnson, 2013). In our study, the average area of the developed land was $30.5 \%$ within a $175-\mathrm{m}$ radius of the lawn sites, which was significantly higher than that of the wheat $(16.5 \%)$ and native grasslands $(4.5 \%)$ (Table 1$)$. The area of the developed land significantly affected the mean soil temperature $\left(\mathrm{F}_{1,7}=6.69, p=0.036 ; r^{2}=0.489\right)$. In addition to the temperature response, the soil carbon dioxide efflux was demonstrated to be significantly limited by the soil water content and was a crucial limiting factor, especially in the arid and semiarid region (Shen et al., 2008; Makhado and Scholes, 2011). In this study, the soil water content varied significantly among the three land-use types (Fig. 4b), and therefore, the contributions of moisture to carbon dioxide efflux is significantly different in lawns, wheat fields and native grasslands. One probable cause of the discrepancy was the limited soil microbial diversity and activity and root respiration because of the low soil water content; in contrast, too much water in the soil pore space restricted or slowed diffusion of carbon dioxide efflux out of the soil profile (Cook and Orchard, 2008; Nusier and Rousan, 2008). However, our soil water content did not significantly influence the soil carbon dioxide efflux when incorporated into the multiple-factor regression model; the influence of soil water on soil respiration was probably offset by soil other factors (e.g., soil temperature and organic fractions). Furthermore, the soil active organic carbon fractions have been suggested as potential drivers for contrasting the microbial activities associated with the soil carbon influx between the land-use types (Wei et al., 2012). However, our results demonstrate that the soil temperature associated with land-use changes was the greatest sensitivity factor of soil respiration under the urbanization background. This result may be related with the effect of the study scales of the soil environment, including abiotic and biotic factors.

In China and at a global scale, urbanization processes, such as the conversion of agricultural fields to urban lawns, is a major component of environmental change (Siciliano, 2012). In our study, urban lawns had a higher soil carbon dioxide efflux during the growing season. Meanwhile, there is widespread concern that urbanization causes a net increase in the atmospheric carbon dioxide. Thus, the issue of the sequestration of carbon in agricultural and residential soils must be clarified to more fully understand the dynamics of local carbon cycling in an urban ecosystem. Several studies have evaluated the carbon sequestration potential of agricultural and urban soils at a local scale (Pouyat et al., 2002; Pataki et al., 2006; Lal, 2008). Zirkle et al. (2011) reported that home lawns in the USA can be a net sink for atmospheric carbon dioxide under all three evaluated levels of management practices (mowing, irrigating, and fertilizing). In addition, a study indicated that the soil nitrous oxide and carbon dioxide emissions in ornamental lawns during management were offset by the soil carbon sequestration according to Townsend-Small and Czimczik (2010). However, the impacts of urbanization on regional ecosystem functions and the global carbon cycle are not entirely clear (Pataki et al., 2006; Hutyra et al., 2011). Thus, future studies on the impacts of urbanization on soil carbon cycling explicitly including how land-use change impacts soil temperature and subsequently influences soil respiration should be investigated at the regional and global scales.

\section{Conclusions}

In conclusion, our study demonstrated that the anthropological land-use changes, especially urban lawn development, increased both the weekly and the daily soil carbon 
dioxide efflux in summer. Although soil microbes and active organic carbon are important factors controlling soil respiration, the soil carbon dioxide efflux at our site was predominantly influenced by the soil temperature and land-use type. The variation in soil moisture among all of the sites was less significant than that of the soil temperature and land-use type. The soil temperature change in three land-use fields is positively correlated with the degree of impervious areas, suggesting that an urban heat island would increase soil carbon emission due to urban development. Thus, how urban land conversion affects the soil carbon dioxide efflux by altering the soil temperature at different scales requires further investigation.

Acknowledgments. We are indebted to Master Liu Lu and Li Baojie for the soil carbon dioxide efflux measurements. This research study was supported by the National Natural Science Foundation of China (No. 41571080).

\section{REFERENCES}

[1] Balogh, J., Pintér, K., Fóti, S., Cserhalmi, D., Papp, M., Nagy, Z. (2011): Dependence of soil respiration on soil moisture, clay content, soil organic matter, and $\mathrm{CO}_{2}$ uptake in dry grasslands. - Soil Biology and Biochemistry 43(5): 1006-1013.

[2] Blair, G.J., Lefroy, R.D.B., Lisle, L. (1995): Soil carbon fractions based on their degree of oxidation, and the development of a carbon management index for agricultural systems. Australian Journal of Agricultural Research 46(7): 1459-1466.

[3] Bowne, D.R., Johnson, E.R. (2013): Comparison of soil carbon dioxide efflux between residential lawns and corn fields. -Soil Science Society of America Journal 77(3): 856859.

[4] Carlisle, E.A., Steenwerth, K.L., Smart, D.R. (2006): Effects of Land Use on Soil Respiration. - Journal of environmental quality 35(4): 1396-1404.

[5] Chu, J.X., Zhang, X.Q. (2006): Dynamic and fractionalization of soil respiration under three diferent land use/covers in the subalpine region of western Sichuan Province, China. - Acta Ecologica Sinica 26(6): 1693-1700. (in Chinese)

[6] Cook, F.J., Orchard, V.A. (2008): Relationships between soil respiration and soil moisture. - Soil Biology and Biochemistry 40(5): 1013-1018.

[7] Davidson, E., Belk, E., Boone, R.D. (1998): Soil water content and temperature as independent or confounded factors controlling soil respiration in a temperate mixed hardwood forest. -Global change biology 4(2): 217-227.

[8] Davidson, E.A., Ackerman, I.L. (1993): Changes in soil carbon inventories following cultivation of previously untilled soils. - Biogeochemistry 20(3): 161-193.

[9] Duan, Y.P., Meng, X.Z., Wen, Z.H., Chen, L. (2013): Acidic pharmaceuticals in domestic wastewater and receiving water from hyper-urbanization city of China (Shanghai): environmental release and ecological risk. Environ. - Environmental Science and Pollution Research 20(1): 108-116.

[10] Fenn, M.E., Haeuber, R., Tonnesen, G.S., Baron, J.S., Grossman-Clarke, S., Hope, D., Jaffe, D.A., Copeland, S., Geiser, L., Rueth, H.M. (2003): Nitrogen emissions, deposition, and monitoring in the western United States. - Bioscience 53(4): 391-403.

[11] Groffman, P.M., Pouyat, R.V., Cadenasso, M.L., Zipperer, W.C., Szlavecz, K., Yesilonis, I.D., Band, L.E., Brush, G.S. (2006): Land use context and natural soil controls on plant community composition and soil nitrogen and carbon dynamics in urban and rural forests. - Forest Ecology and Management 236(2):177-192.

[12] Groffman, P.M., Williams, C.O., Pouyat, R.V., Band, L.E., Yesilonis, I.D. (2009): Nitrate leaching and nitrous oxide flux in urban forests and grasslands. - Journal of 
environmental quality 38(5): 1848-1860.

[13] Gunawardhana, L.N., Kazama, S. (2012): Using subsurface temperatures to derive the spatial extent of the land use change effect. - Journal of Hydrology 460-461: 40-51.

[14] Hou, Y. (2011): Review of effects of urbanization on soil respiration. - Ecology and Environmental Sciences 20(12):1945-1949. (in Chinese)

[15] Houghton, R. (1994): The worldwide extent of land-use change. - Bioscience(44): 305313.

[16] Houghton, R.A. (2003): Revised estimates of the annual net flux of carbon to the atmosphere from changes in land use and land management 1850-2000. - Tellus 55(2): 378-390.

[17] Hutyra, L.R., Yoon, B., Alberti, M. (2011): Terrestrial carbon stocks across a gradient of urbanization: a study of the Seattle, WA region. - Global Change Biology 17(2): 783-797.

[18] Kaur, K., Jalota, R.K., Midmore, D.J. (2010): Soil respiration rate and its sensitivity to temperature in pasture systems of dry-tropics. - Acta Agriculturae Scandinavica Section B 60(5): 407-419.

[19] Kaye, J., McCulley, R., Burke, I. (2005): Carbon fluxes, nitrogen cycling, and soil microbial communities in adjacent urban, native and agricultural ecosystems. - Global Change Biology 11(4): 575-587.

[20] Kellman, L., Beltrami, H., Risk, D. (2007): Changes in seasonal soil respiration with pasture conversion to forest in Atlantic Canada. - Biogeochemistry 82(1): 101-109.

[21] Koerner, B., Klopatek, J. (2002): Anthropogenic and natural $\mathrm{CO}_{2}$ emission sources in an arid urban environment. - Environmental Pollution 116: S45-S51.

[22] Koerner, B.A., Klopatek, J.M. (2010): Carbon fluxes and nitrogen availability along an urban-rural gradient in a desert landscape. - Urban Ecosystems 13(1): 1-21.

[23] Lal, R. (2008): Promise and limitations of soils to minimize climate change. - Journal of Soil and Water Conservation 63(4): 113A-118A.

[24] Makhado, R.A., Scholes, R.J. (2011): Determinants of soil respiration in a semi-arid savanna ecosystem, Kruger National Park, South Africa. - Koedoe-African Protected Area Conservation and Science 53(1): 1-8.

[25] McCulley, R.L., Boutton, T.W., Archer, S.R. (2007): Soil respiration in a subtropical savanna parkland: Response to water additions. - Soil Science Society of America Journal 71(3): 820-828.

[26] Murty, D., Kirschbaum, M.U., Mcmurtrie, R.E., Mcgilvray, H. (2002): Does conversion of forest to agricultural land change soil carbon and nitrogen? A review of the literature. Global Change Biology 8(2): 105-123.

[27] Ni, K., Ding, W.X., Cai, Z.C., Wang, Y.F., Zhang, X.L., Zhou, B.K. (2012): Soil carbon dioxide emission from intensively cultivated black soil in Northeast China: nitrogen fertilization effect. - Journal of Soils and Sediments 12(7): 1007-1018.

[28] Norman, J., Kucharik, C., Gower, S., Baldocchi, D., Crill, P., Rayment, M., Savage, K., Striegl, R. (1997): A comparison of six methods for measuring soil-surface carbon dioxide fluxes. - Journal of Geophysical Research 102(D24): 28771-28777.

[29] Nusier, O.K., Rousan, L.M. (2008): Soil air permeability and carbon dioxide flux measurements from the soil surface. - Soil Science and Plant Analysis 39 (9-10): 14061415.

[30] Pataki, D., Alig, R., Fung, A., Golubiewski, N., Kennedy, C., McPherson, E., Nowak, D., Pouyat, R., Romero, L.P. (2006): Urban ecosystems and the North American carbon cycle. - Global Change Biology 12(11): 2092-2102.

[31] Pickett, S., Cadenasso, M., Grove, J.M., Boone, C.G., Groffman, P.M., Irwin, E., Kaushal, S.S., Marshall, V., McGrath, B.P., Nilon, C.H. (2011): Urban ecological systems: Scientific foundations and a decade of progress. - Journal of Environmental Management 92(3): 331-362.

[32] Pouyat, R., Groffman, P., Yesilonis, I., Hernandez, L. (2002): Soil carbon pools and fluxes in urban ecosystems. - Environmental pollution 116(S1): S107-S118. 
[33] Powlson, D., Whitmore, A., Goulding, K. (2011): Soil carbon sequestration to mitigate climate change: a critical re-examination to identify the true and the false. - European Journal of Soil Science 62(1): 42-55.

[34] Raciti, S.M., Groffman, P.M., Jenkins, J.C, Pouyat, R.V, Fahey,T.J., Pickett, S.T., Cadenasso, M.L. (2011): Accumulation of carbon and nitrogen in residential soils with different land-use histories. - Ecosystems 14(2): 287-297.

[35] Raich, J.W., Potter, C.S. (1995): Global patterns of carbon dioxide emissions from soils. Global Biogeochemical Cycles 9(1): 23-36.

[36] Schimel, D.S., Participants, V., Braswell, B. (1997): Continental scale variability in ecosystem processes: models, data, and the role of disturbance. - Ecological Monographs 67(2): 251-271.

[37] Shen, W.J., Wu, J.G., Grimm, N.B., Hope, D. (2008): Effects of urbanization-induced environmental changes on ecosystem functioning in the Phoenix metropolitan region, USA. - Ecosystems 11(1): 138-155.

[38] Sheng, H., Yang, Y.S., Yang, Z.J., Chen, G.S., Xie, J.S., Guo, J.F., Zou, S.Q. (2010): The dynamic response of soil respiration to land-use changes in subtropical China. - Global Change Biology16(3): 1107-1121.

[39] Siciliano, G. (2012): Urbanization strategies, rural development and land use changes in China: A multiple-level integrated assessment. - Land use policy 29(1): 165-178.

[40] Tian, S.Z., Ning, T.Y., Wang, Y., Li, H.J., Zhong, W.L., Li, Z.J. (2010): Effects of different tillage methods and straw-returning on soil organic carbon content in a winter wheat field. - Chinese Journal of Applied Ecology 21(2): 373-378. (in Chinese)

[41] Townsend-Small, A., Czimczik, C.I. (2010): Carbon sequestration and greenhouse gas emissions in urban turf. -Geophysical Research Letters 37(2): 1-5.

[42] Trusilova, K., Churkina, G. (2008): The response of the terrestrial biosphere to urbanization: land cover conversion, climate, and urban pollution. - Biogeosciences 5(6): 1505-1515.

[43] Wei, Z.Q., Wu, S.H., Zhou, S.L., Li, J.T., Zhao, Q.G. (2014): Soil organic carbon transformation and related properties in urban soil under impervious surfaces. Pedosphere 24(1): 56-64.

[44] Zhao, R.Q., Huang, X.J., Zhong, T.Y., Chuai, X.W. (2012): Carbon Storage and Fluxes of Different Land Use Types in Nanjing. - Journal of Soil and Water Conservation 26(6): 164-170. (in Chinese)

[45] Zheng, S.Q., Wang, R., Glaeser, E.L., Kahn, M.E. (2011): The greenness of China: household carbon dioxide emissions and urban development. - Journal of Economic Geography 11(2): 761-792.

[46] Zhu, Q., Liao, K. H., Xu, Y., Yang, G.S., Wu, S.H., Zhou, S.L. (2012): Monitoring and prediction of soil moisture spatial-temporal variations from a hydropedological perspective: a review. - Soil Research 50(8): 625-637.

[47] Zirkle, G., Lal, R., Augustin, B. (2011): Modeling carbon sequestration in home lawns. HortScience 46(5): 808-814. 